\title{
Building a STEM Mentoring Program in an Economically Disadvantaged Rural Community
}

\author{
Seema Rivera \\ Clarkson University \\ Jennifer M. Knack \\ Clarkson University \\ Kathleen Kavanagh \\ Clarkson University \\ Joshua Thomas \\ Clarkson University \\ Mary Margaret Small \\ Clarkson University

\section{Michael Ramsdell \\ Clarkson University}

\begin{abstract}
Rural, economically disadvantaged communities face a bigger challenge than urban communities in recruiting and retaining high school (HS) students in science, technology, engineering, and mathematics (STEM) because many of these students do not have access to high-quality STEM opportunities. In this article, we describe a mentoring program we developed as part of a larger New York State education grant. This program was implemented in a rural community to connect undergraduate STEM students with HS students to increase HS students' interest in these fields. In this program, HS students visited colleges, explored their interests in STEM, and learned about opportunities available to them in college and beyond. Here, we share the challenges and the successful strategies in implementing a mentoring program in a rural, economically disadvantaged region. The ideas described in the article were designed so other educators can gain insight on how to set up successful mentoring programs to attract and retain students in the STEM pipeline.
\end{abstract}

Keywords: STEM, mentoring, rural

\section{Introduction}

Broadening participation in the science, technology, engineering, and mathematics (STEM) workforce is a priority for the United States. According to the U.S. federal government's 5-year strategic plan for STEM education, to remain competitive in the global economy, the United States needs to improve recruitment and retention in these fields (National Science and Technology Council Committee on STEM Education, 2018). By the time students graduate high school (HS), few are interested and proficient in STEM (Business Higher Education Forum, 2011). The pace at which students graduate in STEM fields is not keeping up with workforce needs. Rural communities have a challenge recruiting and retaining students

This article was supported by a New York State Education Department Science and Technology Entry Program grant awarded to co-PIs Kathleen Kavanagh and Michael Ramsdell. 
in STEM because many students do not have access to high-quality opportunities (National Science and Technology Council Committee on STEM Education, 2018). Socioeconomics, lack of access to STEM careers, and lack of qualified teachers are just some difficulties in engaging rural students in these fields. Thus, it is imperative to support the proliferation of STEM ecosystems and bring together stakeholders to stir student interest in STEM. One course of action to reach this goal is by offering high-quality mentoring to students.

The purpose of this article is to provide information about the challenges and successes we encountered while implementing a HS mentoring program in a rural, geographically isolated, and economically disadvantaged region in upstate New York. We first review the literature to identify concerns about developing a mentoring program in rural, low-income communities and the need to foster interest in STEM during HS. We then outline the larger New York State Education Department (NYSED) Science and Technology Entry Program (STEP) grant implemented at Clarkson University and describe the necessity for a targeted STEM-focused mentoring program for students in Grades 10-12. We then describe the mentoring program implemented in January 2014. We conclude by identifying thematic topics to consider when implementing and establishing a STEM mentoring program under these conditions.

\section{Rural Community-Specific Concerns}

Rural communities face distinct challenges in mentoring HS students in STEM. For example, it is difficult to staff rural schools due to high turnover rates, and teachers tend to have a background in science at a more general level. Teachers in rural communities have fewer professional development opportunities and lack support services. Being geographically isolated also influences parents' expectations for their children such as not envisioning their child going to college (Kilpatrick \& Fraser, 2018; Lyons, Cooksey, Panizzon, Parnell, \& Pegg, 2006), and parents and children may not meet many STEM professionals (Munn et al., 2018). Students also may be limited in what courses are offered in rural schools (Burton et al., 2014). Moreover, rural communities are generally socioeconomically disadvantaged (SD) populations and have higher dropout rates (Burton et al., 2014). There is, however, a benefit to these schools. Small, rural communities tend to be very strong and are usually marked by a close connection with students, their families, and school officials.

The expectation of attending college poses another challenge for rural students, especially for SD students. Traditional predictors of educational success include higher family income and the number of college graduates in the family (Stage \& Rushin, 1993). However, rural students are attending college at a similar rate to their peers in differing geographic areas (Kena et al., 2015). One factor that may help rural students keep up with their peers is community capital, that is, the closeness between families, students, teachers, and other school staff. Community capital in rural HS communities has had positive effects on student achievement and student goals beyond graduation (Byun, Meece, \& Irvin, 2012; Byun, Meece, Irvin, \& Hutchins, 2012; Israel et al., 2001). However, it is unclear how community capital converts into educational success (Dika \& Singh, 2002).

\section{HS Student Interest in STEM}

HS student interest in STEM depends upon factors that include but are not limited to family, school, and personal interest. Bottia, Stearns, Mickelson, Moller, and Parker (2015) examined how HS student experiences were related to choosing a STEM major in college. Their recommendations included providing a variety of learning experiences that complement students' interest in STEM, increasing the quality of academic preparation, and increasing the availability of STEM-related extracurricular experiences accessible to students. 
Hall, Dickerson, Batts, Kauffmann, and Bosse (2011) examined three important factors including (a) what influenced HS students' interest in STEM careers, (b) how the knowledge of school officials and parents impacted the major students choose in college, and (c) what influenced current engineering college students. Their results confirmed parents and teachers were strong factors. Parents and teachers, however, may not know about STEM careers or what coursework will best prepare students to succeed in college. Hall et al. (2011) stated students need to know about STEM careers, and with the support of their parents and teachers, they may strongly consider these pathways. Using longitudinal data, Chen and Weko (2009) found a high percentage of students who enter STEM fields had strong academic preparation and were from families with a strong academic background.

\section{Challenges of Creating a Formal Mentor Program}

Some researchers have indicated the difficulty of setting up formal mentoring programs and noted the lack of rigorous scientific evidence about the benefits of mentoring relationships (e.g., DuBois, Holloway, Valentine, \& Cooper, 2002; Rhodes, 2008). Even when concluding there are benefits, there is inconsistency about which aspects of mentoring are most effective. Some of the inconsistency comes from the difference in program objectives such as reducing problem behavior or increasing interest in going to college.

In their meta-analysis, DuBois et al. (2002) noted at-risk youth were most likely to benefit from mentoring. One possible explanation is the cultural capital, or social knowledge and behaviors, that mentees develop through the mentoring experience (Philip \& Hendry, 2000). Because we created our mentoring program geared for students from rural, SD families, we wanted to increase students' cultural capital by increasing the number of college students and faculty/staff members with whom HS students interacted.

A fundamental component of mentoring programs is to determine how mentoring relationships are formed. In some cases, students select their own mentors (e.g., Philip \& Hendry, 2000), whereas in other programs, students are assigned mentors (e.g., Cox, 2005). According to Allen, Eby, and Lentz (2006), it was beneficial for students to feel like they had input in the mentor matching process. However, Cox (2005) argued that putting significant resources (e.g., investing a lot of time in determining mentor matches) into matching mentor pairs on factors such as personality is not necessary for strong mentor relationships.

\section{Context}

\section{NYSED STEP Grant}

In 2006, we were awarded a NYSED STEP grant for rural St. Lawrence County in upstate New York. We named our program Integrated Mathematics and Physics for Entry to Undergraduate STEM (IMPETUS) for Career Success. St. Lawrence County is the largest county in New York covering 2,840 square miles. Approximately 15,000 students in grades K-12 are educated in 17 rural school districts including small districts of 350 students to a few larger districts of nearly 3,000 students. All districts share similar problems of limited resources and a "high-needs" population.

The primary goal of the CU STEP IMPETUS for Career Success program (referred to moving forward as CU STEP) is to provide opportunities for underrepresented minorities and students from SD rural areas to realize their potential for college entry as STEM majors and eventual career success in STEM-oriented professions. The program now includes multiple components including (a) a roller coaster summer camp, (b) a roller coaster design competition during the academic year, (c) afterschool STEM enrichment activities, (d) tutoring, (e) opportunities to conduct and present research, and (f) teacher professional development. 
Although CU STEP has been largely successful, students had waning interests in many of the program components when they entered 10th grade. Retention in the program is important for students to continue building the skills and knowledge base needed for college and for having support while applying to college. The Integrated Clarkson Experience (ICE) mentoring program was designed to be a retention bridge between CU STEP and beginning college. This program was specifically designed to serve the older HS students in the larger CU STEP. The ICE mentoring program facilitates college mentors sharing their academic, research, and personal experiences with HS mentees and offering encouragement to promote self-confidence, self-esteem, and academic success. We anticipated college mentors would have a significant impact on the CU STEP students by conveying first-hand evidence of student, college, and career success.

\section{Evidence of Need for Targeted STEM Education Programs in Rural, Low-Income Areas}

Our county is similar to other rural communities in the United States in that we have a high number of SD families residing across multiple school districts that have limited resources. A comprehensive assessment of local school districts' needs identified three specific categories of need: (a) student academic achievement, (b) poverty and at-risk students, and (c) college preparation.

A central concern driving the development of the program was students' low academic achievement. In 2018, standardized test data in mathematics indicated only $36 \%$ of St. Lawrence County students in Grades 3-8 had proficiency levels compared to the $45 \%$ state level. Moreover, only $27 \%$ of the SD population scored at a proficient level. A HS diploma or GED is the highest education level for roughly $36 \%$ of the population (New York State Community Action Association, 2017). This academic underachieving for students in the county, particularly for SD students, indicates a need for additional STEM-focused education.

A second concern is that the communities being served are characterized by poverty. The per-capita income is well below that of New York with a median household income of roughly $\$ 46,000$ in 2017 compared to $\$ 60,000$ for the state. The New York State Annual Poverty Report (New York State Community Action Association, 2017) reported that 29.7\% of St. Lawrence County children under 18 years of age live below the poverty level compared to the state average of $20.8 \%$, with a countywide poverty rate of $19 \%$. In addition, $53 \%$ of the county's children qualify for free and reduced lunches.

A third concern is students' preparation for college. According to the 2016-2017 countywide data for St. Lawrence County, only $31 \%$ and $69 \%$ of graduating HS seniors were considered "proficient" (i.e., $85 \%$ mastery) in math and science, respectively. Proficiency rates among SD graduating HS seniors were lower, with only $18 \%$ in math and $55 \%$ in science. These low proficiency scores are not surprising given that there is a decrease in the number of students taking typical ninth-grade classes (e.g., Algebra 1) to upper level classes. In other words, most students are not adequately prepared to enter STEM majors. Our program was therefore designed to expose students to STEM concepts and increase students' interest in STEM fields. However, 14 of the districts are classified as "high needs" by NYSED, indicating that these districts do not have sufficient local resources. Given that SD students are not meeting academic proficiency standards, we designed our mentoring program to target HS students from SD families and retain them through HS graduation.

\section{Developing and Implementing a Mentoring Program}

The main goals of ICE were to (a) retain 10th-12th graders in CU STEP through HS graduation, (b) support HS students' college search and college application process, (c) help HS students understand what college life is like (e.g., class schedules, getting involved in student clubs) and the resources available (e.g., the Collegiate Science and Technology Entry Program [CSTEP], tutoring, financial aid), and (d) increase confidence in HS student's ability to be a college student. Because the STEP grant has an 
emphasis on preparing students for STEM careers, we also aimed to have students enroll in a STEM major.

To achieve the program aims, the mentoring program needed to be flexible to accommodate HS and college students' busy and often variable schedules. For example, HS students in our program play seasonal sports, join clubs, or start a part-time job. College students' course schedules change each semester, and they may join other campus organizations or a research team, study abroad, or start a job. Due to serving a rural, low-income population across multiple school districts, our program needed to offer multiple ways for mentor pairs to interact in the likely case that transportation and internet access were not reliably available. Moreover, given the literature reviewed above, the program needed to provide HS students with opportunities to be exposed to STEM in ways that connected with their lives (Avery \& Kassam, 2011). Here, we highlight three program components used to achieve program goals: mentor pairs, Roadmap to College, and campus visits.

\section{Mentor Pairs}

The central component of the mentoring program was pairing HS students with college mentors. HS and college students each completed profiles to provide information about themselves such as hobbies, classes they do well in, and job/career interests. College students also provided information about why they wanted to be a mentor as a way to determine their motivation and commitment to the program. Mentormentee pairs were first matched by gender and then matched by interest in majors and career paths. However, we prioritized matching the mentor and mentee quickly rather than forming a perfect match (Cox, 2005).

Mentor pairs served several functions. First, mentor pairs provided access to college students and information about college (e.g., resources available including CSTEP [the NYSED college-level counterpart of STEP], tutoring, writing help, professors' office hours, and accommodation services). College mentors shared their effective study strategies and helped their mentees build confidence and skills to transition into successful college students. Many ICE students are first-generation students and therefore benefited from having information about the transition from HS to college. Second, family and peer networks are among the most influential factors in whether rural students' aspire to attend college (Chenoweth \& Galliher, 2004); we believed adding a college mentor to their existing network would bolster their college aspirations. Many ICE students expressed concern about not having a network of people at college; it was helpful for college mentors to share concerns they had about starting college and how they overcame these concerns (e.g., joined CSTEP, attended office hours, arranged tutoring). Third, mentors conveyed both the excitement of being in college (e.g., interesting classes, often increased independence) and realities of the workload.

\section{Roadmap to College}

We designed Roadmap to College booklets to introduce students to grade-appropriate information they should be considering as they began preparing for college. These booklets also gave mentor pairs a specific topic to discuss each month to help stimulate conversation. Different versions of the booklets were created for 10th, 11th, and 12th grades (see Figure 1). For example, in October, sophomores identified effective learning and study strategies as well as classes, hobbies, and activities they found interesting. In November, sophomores started to build a resume. 


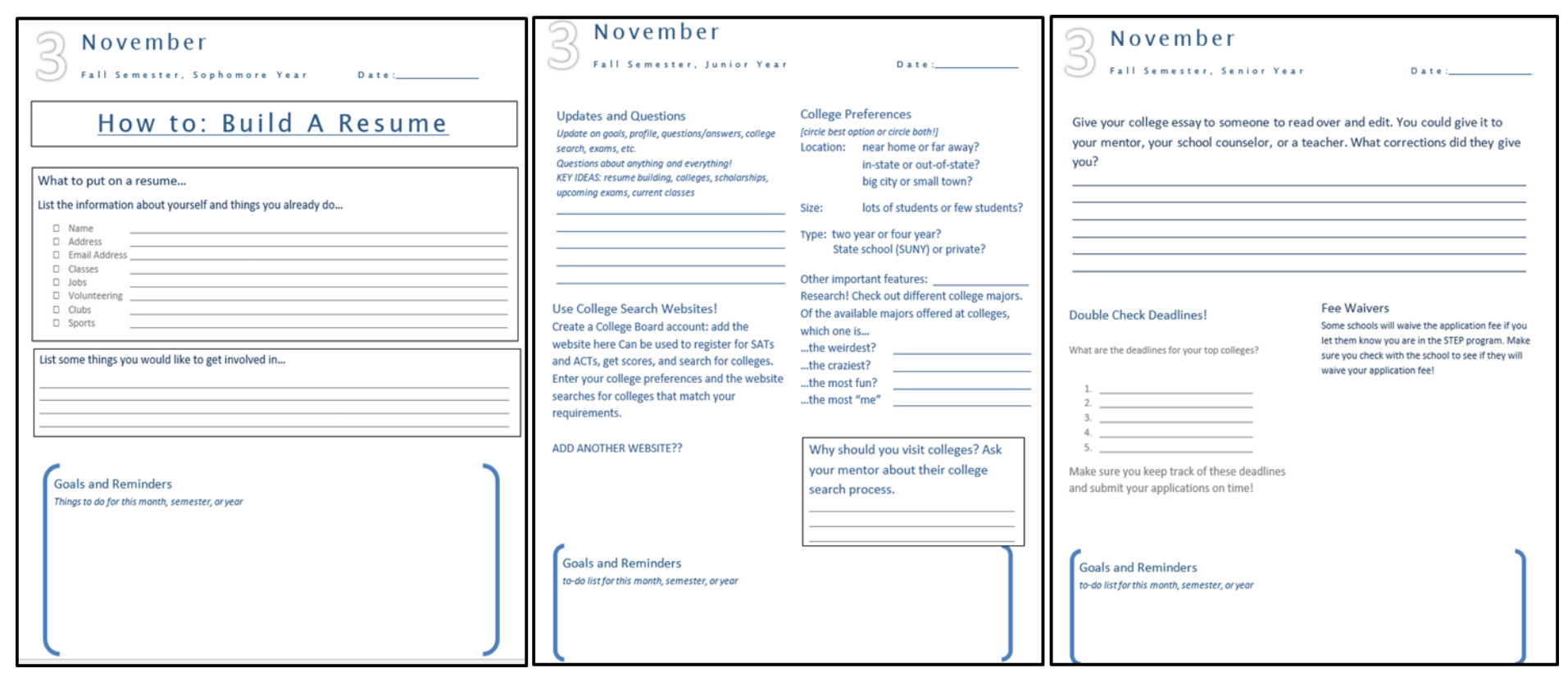

Figure 1. Sample Month of Roadmap to College for Sophomores, Juniors, and Seniors

\section{College Visits}

Another program component was visiting local colleges. Through the larger CU STEP, ICE students came to Clarkson University once a month during the academic year for academic and career workshops to build STEM-related skills and knowledge. ICE students frequently convened in smaller groups (i.e., without the younger CU STEP students) for college-focused discussions and activities.

We also arranged special ICE visits to local colleges. These campus visits more closely resembled college visits that HS students make to gather information about a specific school. We typically arranged a campus tour, a meeting with CSTEP staff/students, a presentation by admissions, and lunch. In some visits, we were able to arrange for HS students to attend a college class. These campus visits have been successful in stimulating discussion about college (e.g., possibilities about majors) and increasing excitement about attending college. We also encouraged HS students to attend college open houses and participate in HS college fairs.

\section{Outcomes of the Mentoring Program}

Based on our experiences implementing this mentoring program, we identified thematic topics to consider when creating a STEM program in rural economically disadvantaged regions. The most salient themes are described below and include flexibility, communication with rural HS students, social capital, and facilitating access to information about college.

\section{Importance of Flexibility}

Flexibility in being able and willing to change how program components were implemented is essential for a successful mentoring program. As the program grew, we strove to integrate the ICE focus on 10th12th graders into the larger CU STEP. For example, during regular monthly campus visits, we often broke out into smaller groups with the 10th-12th graders to focus on college preparation. In one such session, college students shared how they selected colleges to apply to and what aspects they liked about their college. Then, as a group, we brainstormed what things might be important in selecting a college 
(e.g., availability of dorms on campus) and how some things mattered more for some people. In addition to being beneficial to HS students, the ICE break-out sessions on college preparation gave younger students something to look forward to as they progressed through CU STEP.

\section{Communication With Rural HS Students}

We experienced some difficulty in facilitating communication between mentor pairs. We intended for college students to meet face to face with their HS mentee during the monthly STEM workshops;

however, many college mentors were in class during this time. This scheduling conflict prevented mentor pairs from interacting face to face and hindered developing strong connections. However, college mentors were directed to be in contact their HS mentee approximately once a week through emails, phone calls, texts, social media, Apple FaceTime, or Google Hangouts (the form of communication varied by mentor pair depending accessibility and preferences). We also encouraged college students to work through the Roadmap to College with their HS student and to discuss their experience of transitioning to college and help their mentee build confidence in their ability to be a college student.

Even once a mentoring relationship was initiated, sustaining the relationship was often difficult given geographical and socioeconomic limitations. Many mentor pairs regularly communicated multiple times each week. However, many ICE students had unreliable Internet and phone services and were unable to regularly check their social media accounts or text messages to interact with their mentors. One way we addressed this issue was to allow teachers to check out Internet hotspots that students could take home. Even if students had regular access, parents sometimes took away phone or Internet privileges, and some schools' servers restricted or blocked emails from outside the school. Even when mentors were successfully able to send an email or social media message, HS students did not always respond. This led to college mentors feeling discouraged and questioning whether they were contributing in meaningful ways. In the future, we plan to address this obstacle by involving parents. For example, we intend to communicate with parents about who their adolescent was matched with and what topics are being discussed in the Roadmap to College.

\section{Building Social Capital}

We received feedback that indicated ICE students benefited from interacting with multiple college students during the monthly campus visits and having a specific college mentor. This benefit seemed to occur regardless of whether there was regular in-depth reciprocal dialogue. Even when HS students did not respond to their mentors' emails, the unanswered messages still seemed to have positive impacts on HS students. For example, HS students often commented they were excited to get a message from their mentor even if the HS student did not actually reply to the mentor. HS students also shared information with us about what their mentor was doing (e.g., mentor preparing for a research presentation).

Moreover, participation in the ICE program broadened the number of college personnel ICE students interacted with including admissions counselors/directors, CSTEP staff, and professors. They heard college students share stories about their concerns about college, hurdles they encountered, and connecting with resources to succeed. The personal stories that seemed to resonate most were accounts of finding on-campus jobs while still doing well in school and specific information about who they turned to for support and encouragement. Exposure to a similar support network that they have in their HS seemed to be a reassurance and helped make the concept of becoming a college student more accessible.

\section{Facilitating Access to Information About College}

Arguably one of the most successful and appealing aspects of the program was the campus visits to local colleges. College visits stimulated discussion about possible majors, groups to get involved in, various support, and whether they would live on or off campus. Campus visits sparked interest about college and 
bridged the gap between being a HS student and envisioning themselves as a college student. On the way home after a college visit, students (who had been on several campus visits through ICE and had participated in the monthly workshops) discussed the pros and cons of schools based on the campus visits they attended and information they gathered on their own; they had reached the point where they were discussing why they preferred one school over another. Although one college visit may not be enough to determine if the project objectives were met, the visits had an obvious impact on the students. This example suggested students felt supported in their college search, understood what college life is like, understand the resources available, and were more confident about their ability to be a college student (which were main goals of the program).

\section{Recommendations}

Based on our experiences implementing the mentoring program, we have several recommendations to offer for people interested in starting a mentoring program. First, we recommend regularly reviewing the program and making adjustments. For example, 1 year, we sent emails to HS students and their mentors to create the initial mentor link. This process worked well that year but was unsuccessful the following year. As a result, we plan to talk individually with HS students either at the monthly campus visits or by phone to share this information. Program organizers need to be willing and able to change components of the program as needed.

Second, facilitating communication between mentors and mentees is important. The Roadmap to College provided a common ground for starting dialog; we recommend having a similar document to facilitate dialog. We also found good communication with teachers supported stronger mentoring relationships; we recommend involving teachers who encourage HS students to respond to their college mentors.

Finally, it important to consider the major purpose of the mentoring program. Although we aimed for our mentoring program to satisfy multiple objectives, our priority was to help HS students build community capital to understand the social networks and resources available at college. We recommend a focus on building community capital.

\section{Conclusions}

The aims of this article were to (a) identify challenges and successes in recruiting students into STEM disciplines in isolated rural, SD areas and (b) share the mentoring program we developed. From this article, other universities in rural areas gain insight on how to set up similar mentoring programs. The most significant message is the importance of having program flexibility to address concerns around mentor-mentee communication, building social capital, and boosting interest about college and STEM.

It is worth noting that some challenges in developing a mentoring program are shared in rural and urban areas. However, rural areas_-particularly SD regions—-have unique challenges. For example, in rural regions there are often obstacles due to the large geographical area being served. In our program, some districts had to bus their students nearly an hour in each direction to attend monthly campus visits. These long bus rides are especially difficult after a full day of school and result in students arriving home very late. In addition, in rural areas there are often fewer modes of public transportation. In our program, the lack of reliable transportation as well as inconsistent email and phone access made it difficult for mentor-mentee pairs to meet face to face.

We saw an increase in students staying in CU STEP through graduation. However, in rural areas, there are often small numbers of students eligible for graduation in a given year which make well-powered quantitative studies challenging. Moreover, given the variation in the small local districts, it is difficult to conduct intervention studies to determine which aspects of the mentoring program are effective.

However, continuing to grow and build these STEM ecosystems are essential in advancing the development of STEM in the United States. Mentoring programs such as this ICE program fosters STEM 
ecosystems that support students from rural, low-income families to pursue higher education in STEM fields.

\section{References}

Allen, T. D., Eby, L. T., \& Lentz, E. (2006). Mentorship behaviors and mentorship quality associated with formal mentoring programs: Closing the gap between research and practice. Journal of Applied Psychology, 91, 567-578. doi:10.1037/0021-9010.91.3.567

Avery, L. M., \& Kassam, K.-A. (2011). Phronesis: Children's local rural knowledge of science and engineering. Journal of Research in Rural Education, 26, 1-18. Retrieved from http://jrre.psu.edu/articles/26-2.pdf

Bottia, M. C., Stearns, E., Mickelson, R. A., Moller, S., \& Parker, A. D. (2015). The relationships among high school STEM learning experiences and students' intent to declare and declaration of a STEM major in college. Teacher College Record, 117, 1-46. doi:10.1080/09500693.2017.1341067

Burton, E. P., Kaminsky, S. E., Lynch, S., Behrend, T., Han, E., Ross, K., \& House, A. (2014). Wayne School of Engineering: Case study of a rural inclusive STEM-focused high school. School Science and Mathematics, 114, 280-290.

Business Higher Education Forum. (2011). Meeting the STEM workforce demand: Accelerating math learning among students interested in STEM. Retrieved from https://www.bhef.com/sites/default/files/BHEF_2011_accelerating_math.pdf

Byun, S., Meece, J. L, \& Irvin, M. J. (2012). Rural-nonrural disparities in postsecondary educational attainment revisited. American Educational Research Journal, 49, 412-437. doi:10.3102/0002831211416344

Byun, S., Meece, J. L., Irvin, M. J., \& Hutchins, B. C. (2012). The role of social capital in educational aspirations of rural youth. Rural Sociology, 77, 355-379.doi:10.1111/j.1549-0831.2012.00086.x

National Science and Technology Council Committee on STEM Education. (2018). Charting a course for success: America's strategy for STEM education. Retrieved from https://www.whitehouse.gov/wpcontent/uploads/2018/12/STEM-Education-Strategic-Plan-2018.pdf

Chen, X., \& Weko, T. (2009). Students who study science, technology, engineering, and mathematics (STEM) in postsecondary education (NCES \#2009-161). Washington, DC: U.S. Department of Education. Retrieved from http://nces.ed.gov/pubs2009/2009161.pdf

Chenoweth, E., \& Galliher, R. V. (2004). Factors influencing college aspirations of rural West Virginia high school students. Journal of Research in Rural Education, 19, 1-14. Retrieved from http://jrre.psu.edu/articles/19-2.pdf

Cox, E. (2005). For better, for worse: The matching process in formal mentoring schemes. Mentoring \& Tutoring: Partnership in Learning, 13, 403-414. doi:10.1080/13611260500177484

DuBois, D. L., Holloway, B. E., Valentine, J. C., \& Cooper, H. (2002). Effectiveness of mentoring programs for youth: A meta-analytic review. American Journal of Community Psychology, 30, 157-197.

Dika, S. L., \& Singh, K. (2002). Applications of social capital in educational literature: A critical synthesis. Review of Educational Research, 72, 31-60. doi:10.3102/00346543072001031

Hall, C., Dickerson, J., Batts, D., Kauffmann, P., \& Bosse, M. (2011). Are we missing opportunities to encourage interest in STEM fields? Journal of Technology Education, 23, 32-46. Retrieved from https://files.eric.ed.gov/fulltext/EJ965337.pdf

Israel, B. A., Parker, E. A., Rowe, Z., Salvatore, A., Minkler, M., López, J., . . Halstead, S. (2001). Community-based participatory research: Lessons learned from the Centers for Children's 
Environmental Health and Disease Prevention Research. Environmental Health Perspectives, 113, 1463-1471. doi:10.1289/ehp.7675

Kena, G., Musu-Gillette, L., Robinson, J., Wang, X., Rathbun, A., Zhang, J., . . Dunlop Velez, E. (2015). The condition of education 2015 (NCES 2015-144). Washington, DC: U.S. Department of Education, National Center for Education Statistics.

Kilpatrick, S., \& Fraser, S. (2019). Using the STEM framework collegially for mentoring, peer learning and planning. Professional Development in Education, 45, 614-626. doi:10.1080/19415257.2018.1463925

Lyons, T., Cooksey, R., Panizzon, D., Parnell, A., \& Pegg, J. (2006). Science, ICT and mathematics education in rural and regional Australia: The SiMERR national survey. Armidale, Australia: University of New England.

Munn, M., Griswold, J., Starks, H., Fullerton, S. M., Viernes, C., Sipe, T. A., . . Levias, S. (2018). Celebrating STEM in rural communities: A model for an inclusive science and engineering festival. Journal of STEM Outreach, 1, 1-11. doi:10.15695/jstem/v1i1.4

New York State Community Action Association. (2017). New York State annual poverty report. Retrieved from http://nyscommunityaction.org/PovReport/2016/Poverty\%20Report_2017_Master\%20Doc.pdf

Philip, K., \& Hendry, L. B. (2000). Making sense of mentoring or mentoring making sense? Reflections on the mentoring process by adult mentors with young people. Journal of Community \& Applied Social Psychology, 10, 211-223. doi:0.1002/1099-1298(200005/06)10:3<211::AIDCASP569>3.0.CO;2-S

Rhodes, J. E. (2008). Improving youth mentoring interventions through research-base practice. American Journal of Community Psychology, 41, 35-42. doi:10.1007/s10464-007-9153-9

Stage, F., \& Rushin, P. (1993). A combined model of student predisposition to college and persistence in college. Journal of College Student Development, 34, 276-282.

The Journal of Educational Research and Practice provides a forum for studies and dialogue that allows readers to better develop social change in the field of education and learning. Journal content may focus on educational issues of all ages and in all settings. It also presents peer-reviewed commentaries, book reviews, interviews of prominent individuals, and additional content. The objectives: We publish research and related content that examines current relevant educational issues and processes aimed at presenting readers with knowledge and showing how that knowledge can be used to impact social change in educational or learning environments. Additional content provides an opportunity for scholarly and professional dialogue regarding that content's usefulness in expanding the body of scholarly knowledge and increasing readers' effectiveness as educators. The journal also focuses on facilitating the activities of both researcher-practitioners and practitioner-researchers, providing optimal opportunities for interdisciplinary and collaborative thought through blogging and other communications. Walden University Publishing: http://www.publishing.waldenu.edu 